\title{
List of Annexes
}

Annex I. All known treaty-based cases as of 30 January 2019

Annex II. Cases excluded from assessment (publicly unavailable awards and decisions, or available awards and decisions in languages other than English or Russian)

Annex III. Cases with publicly available awards and decisions in English or Russian language (the basis for assessment)

Annex IV. Cases with elements of contract interpretation

Annex $v$. Cases with the application of national law to contract interpretation (interpretative rules of national laws)

Annex VI. Cases with the application of national law to contract interpretation (interpretation in light of various other rules of national laws)

Annex VII. Model BITs as of 30 January 2019

Annex VIII. Analysed IIAs

Annex IX. Provisions of some relevance for contract interpretation in the selected uniform private law conventions

Annex $X$. IIAs with reference to conflict of laws of the host state 